\title{
A novel adamantyl benzylbenzamide derivative, AP736, inhibits melanogenesis in B16F10 mouse melanoma cells via glycogen synthase kinase $3 \beta$ phosphorylation
}

\author{
HONG-JU SHIN ${ }^{1,2 *}$, CHANG TAEK OH ${ }^{3,4 *}$, TAE-RIN KWON ${ }^{3,4}$, HEUNG SOO BEAK ${ }^{5}$, \\ YUNG HYUP JOO ${ }^{5}$, JEONG-HWAN KIM ${ }^{1}$, CHANG SEOK LEE ${ }^{1}$, JOHN HWAN LEE ${ }^{5}$, \\ BEOM JOON KIM ${ }^{3,4}$, SONG SEOK SHIN ${ }^{5}$ and EUN-SEOK PARK ${ }^{2}$
}

\author{
${ }^{1}$ Medical Beauty Research Institute, AmorePacific R\&D Center, Yongin 446-729; ${ }^{2}$ School of Pharmacy, \\ Sungkyunkwan University, Suwon, Gyeonggi-do 440-746; ${ }^{3}$ Department of Dermatology, \\ Chung-Ang University College of Medicine; ${ }^{4}$ Department of Medicine, Graduate School, Chung-Ang University, \\ Seoul 156-756; ${ }^{5}$ Skin Research Institute, AmorePacific R\&D Center, Yongin 446-729, Republic of Korea
}

Received April 7,2015; Accepted August 20, 2015

DOI: $10.3892 / \mathrm{ijmm} .2015 .2348$

\begin{abstract}
Recently, much effort has been made to develop effective dermatological depigmenting compounds. In this study, we investigated the novel candidate compound, AP736 (an adamantyl benzylbenzamide derivative), and its effects on melanogenesis in B16F10 melanoma cells, as well as the mechanisms involved. AP736 has been reported to exert antimelanogenic effects in melanocytes in vitro and in artificial skin equivalents through the inhibition of key melanogenic enzymes and the suppression of the cAMP-protein kinase A (PKA)cAMP response element-binding protein (CREB) signaling pathway. Thus, we examined another pathway of melanogenesis involving the effects of AP736 on the glycogen synthesis kinase $3 \beta$ (GSK3 $\beta$ ) pathway. Melanin content and tyrosinase activity were measured using a spectrophotometer after the cells were treated with AP736. The AP736-induced activation of signaling pathways was examined by western blot analysis. We confirmed that AP736 decreased melanin production in a dose-dependent manner; however, it did not directly inhibit tyrosinase, the rate-limiting melanogenic enzyme. The expression of microphthalmia-associated transcription factor, tyrosinase, and related signal transduction pathways was also investigated. The Wnt signaling pathway is deeply involved in melanogenesis; therefore, phosphorylation by GSK3 $\beta$ was assessed following treatment with AP736. AP736 induced GSK3 $\beta$ phosphorylation (inactivation), but it did not alter the level of $\beta$-catenin. Furthermore,
\end{abstract}

Correspondence to: Professor Eun-Seok Park, School of Pharmacy, Sungkyunkwan University, 2066 Seobu-ro, Jangan-gu, Suwon, Gyeonggi-do 440-746, Republic of Korea

E-mail: espark@skku.edu

*Co-first authors

Key words: B16F10 melanoma cellS, AP736, melanogenesis, tyrosinase, glycogen synthase kinase $3 \beta$ the expression of $\alpha$-melanocyte-stimulating hormone-induced tyrosinase was downregulated by AP736. Our data suggest that AP736 exerts hypopigmentary effects through the downregulation of tyrosinase via GSK3 $\beta$ phosphorylation.

\section{Introduction}

Melanogenesis is the most important function of melanocytes, which are located in the basal layer of the epidermis in human skin $(1,2)$. Melanogenesis has many important physiological functions, including the photoprotection of human skin from ultraviolet (UV) irradiation (3). Melanin synthesis is stimulated by various molecules and conditions, such as $\alpha$-melanocyte-stimulating hormone ( $\alpha$-MSH), cyclic AMP (cAMP)-elevating agents [including forskolin, glycyrrhizin and isobutylmethylxanthine (IBMX)] and UV radiation (4-6). Various dermatologic disorders result from the accumulation of excessive levels of epidermal pigmentation (4-6). Epidermal and dermal hyperpigmentation may depend on either increased numbers of melanocytes or melanogenic enzyme activities (7). Three key melanogenic enzymes, tyrosinase, tyrosinase-related protein-1 (TRP-1), and tyrosinase-related protein-2 (TRP-2), participate in melanogenesis (8). Tyrosinase is the rate-limiting enzyme that catalyzes two critical steps in melanogenesis: the hydroxylation of L-tyrosine to 3,4-dihydroxyphenylalanine (DOPA) and the oxidation of DOPA to dopaquinone (9-11). Dopaquinone is converted to dopachrome, which is in turn converted to dihydroxyindole or dihydroxyindole-2-carboxylic acid (DHICA) to form melanin.

TRP-1 catalyzes the oxidation of DHICA to carboxylated indolequinone (12). Thus, the upregulation or activation of melanogenic enzymes can increase melanogenesis and hyperpigmentation. Additionally, stimulators, such as $\alpha-\mathrm{MSH}$, forskolin and IBMX, regulate the expression of tyrosinase, TRP-1 and TRP-2 by modulating the activation of transcription factors, such as microphthalmia-associated transcription factor (MITF) and cAMP response element-binding protein (CREB) and through protein kinase A (PKA) signaling pathways (13). 
MITF is a master transcription factor for melanogenesis. With a basic helix-loop-helix-leucine zipper (bHLHZip) structure, MITF upregulates tyrosinase, TRP-1 and TRP-2 by binding to an M-box motif at the promoter sites (14). MITF regulates melanocyte pigmentation, proliferation, survival and differentiation (15). Mutation of the MITF gene in humans can cause abnormal pigmentation of the skin and hair $(16,17)$. Moreover, decreased MITF expression induces the downregulation of melanocyte differentiation markers and inhibits melanogenesis (18). A key component of MITF induction is the $\mathrm{UV}$-mediated induction of the proopiomelanocortin (POMC) and $\mathrm{MC1}$ genes encoding $\alpha$-MSH. $\alpha$-MSH binding to MC1R increases the intracellular level of cAMP (19) and activates PKA, which subsequently phosphorylates CREB protein, an activator of MITF gene expression. Conversely, the activation of extracellular signal-regulated kinase (ERK) induces MITF phosphorylation and degradation, ultimately suppressing melanogenesis (20-22). MITF expression is also regulated by the Wnt signaling pathway, the activation of which results in glycogen synthase kinase $3 \beta$ (GSK3 $\beta$ ) inactivation and subsequent $\beta$-catenin accumulation (23). Furthermore, accumulated $\beta$-catenin moves into the nucleus and binds lymphoid-enhancing factor/T-cell factor transcription factor, stimulating MITF expression (24). By contrast, it is known that activated GSK3 $\beta$ leads to the ubiquitination and degradation of $\beta$-catenin (25).

The Wnt/ $\beta$-catenin pathway, which is activated by the interactions of Wnt 1, Wnt3a and Wnt8 with Frizzled $(\mathrm{Fz})$ receptors and low-density lipoprotein receptor-related protein 5/6 co-receptors (26), controls cell differentiation, cell proliferation and cell motility (27-30). In the absence of a Wnt signal, $\mathrm{N}$-terminal serine/threonine residues of $\beta$-catenin are sequentially phosphorylated by casein kinase 1 and GSK3 $\beta$ in a multiprotein complex containing adenomatous polyposis coli and axin $(31,32)$. Phosphorylated $\beta$-catenin is then recognized by F-box beta-transducin repeat-containing protein, a component of the ubiquitin ligase complex, resulting in the degradation of $\beta$-catenin via an ubiquitin-dependent mechanism (33). The activation of the receptor by its Wnt ligands negatively regulates GSK $3 \beta$, leading to the accumulation of cytoplasmic $\beta$-catenin (34). A link between Wnt/ $\beta$-catenin signaling and melanocyte differentiation has been shown by the finding that $\beta$-catenin, which accumulates by the activation of $\mathrm{Wnt} / \beta$-catenin signaling, forms a complex with lymphocyte enhancer factor-1 to upregulate expression of the MITF gene (35). $\beta$-catenin also directly interacts with the MITF protein itself and then activates MITF-specific target genes (36). In addition to MITF, Wnt/ $\beta$-catenin signaling is involved in neural crest formation, migration, proliferation and differentiation (24).

Several known natural melanin synthesis inhibitors, including arbutin and kojic acid, have been the focus of previous studies and are currently being utilized as cosmetic additives (37). A great deal of attention has continuously focused on the development of natural products for future applications in the cosmetics industry $(38,39)$. However, it is necessary to find safer and more effective skin-whitening compounds due to the carcinogenic potential and weak whitening effect of kojic acid.

In the present study, we examined the effects of the novel adamantyl benzylbenzamide derivative, AP736, on melanin synthesis and tyrosinase activity in B16F10 melanoma cells. In addition, we examined the effects of AP736 on the expression of MITF and tyrosinase.

\section{Materials and methods}

Materials. The novel adamantyl benzylbenzamide derivative, AP736, was synthesized at the AmorePacific R\&D Center (structure shown in Fig. 1). AP736 was dissolved in dimethyl sulfoxide (DMSO) and stored at $-20^{\circ} \mathrm{C}$ as a stock solution $(10 \mathrm{mM})$. $\alpha$-MSH, 3,4-dihydroxy-L-phenylalanine (L-DOPA), mushroom tyrosinase, phenylthiourea (PTU), kojic acid and (2'Z,3'E)-6-bromoindirubin-3'-oxime (BIO) were purchased from Sigma-Aldrich Co. (St. Louis, MO, USA). The Cell Counting kit-8 (CCK-8) was purchased from Dojindo Molecular Technologies, Inc. (Kumamoto, Japan). Dulbecco's modified Eagle's medium (DMEM), phosphate-buffered saline (PBS) and penicillin/streptomycin were purchased from WelGene Biopharmaceuticals (Daegu, Korea). Fetal bovine serum (FBS) was purchased from Gibco Life Technologies (Grand Island, NY, USA). Antibodies specific for tyrosinase (C-19), TRP-1 and actin were from Santa Cruz Biotechnology, Inc. (Santa Cruz, CA, USA). Antibodies specific for phosphorylated (p-)GSK3 $\beta$ (\#9336) and total GSK3 $\beta$ (\#9315) were purchased from Cell Signaling Technology (Beverly, MA, USA), and microphthalmia Ab-1 (C5, MS-771-P0) was obtained from NeoMarkers (Fremont, CA, USA). $\beta$-catenin (610154) was from BD Transduction Laboratories (San Diego, CA, USA). Secondary antibodies specific for anti-goat IgG (PI-9500), anti-mouse IgG (PI-2000) and anti-rabbit IgG (PI-1000) were purchased from Vector Laboratories, Inc. (Burlingame, CA, USA).

Cell culture. B16F10 mouse melanoma cells (CRL-6475) were purchased from the American Type Culture Collection (ATCC; Rockville, MD, USA). The cells were maintained in DMEM supplemented with $10 \%$ (v/v) FBS and $1 \%$ penicillin/ streptomycin $(10,000 \mathrm{U} / \mathrm{ml}$ and $10,000 \mu \mathrm{g} / \mathrm{ml}$, respectively) in $5 \% \mathrm{CO}_{2}$ at $37^{\circ} \mathrm{C}$ The cells were cultured every 3 days until a maximal passage number of 20 was achieved.

Cell viability assay. The B16F10 melanoma cells were seeded in 96-well plates $\left(2 \times 10^{4}\right.$ cells/well). After $24 \mathrm{~h}$ of incubation at $37^{\circ} \mathrm{C}$, the medium was replaced with medium containing AP736 diluted to the appropriate concentrations. The control cells were treated with DMSO at a final concentration of $0.1 \%$. After $24 \mathrm{~h}$, the medium containing the compounds or DMSO was replaced with medium containing $10 \%$ CCK-8 solution. The cells were then incubated at $37^{\circ} \mathrm{C}$ for $30 \mathrm{~min}$, and the absorbance was measured at $450 \mathrm{~nm}$ using a spectrophotometer (VersaMax; Molecular Devices, Sunnyvale, CA, USA). All assays were performed in triplicate. The cytotoxic effect was expressed as a percentage of cell viability relative to the untreated control cells. Cell viability was calculated using the following formula: cell viability $(\%)=\left(\mathrm{A}_{\text {sample }} / \mathrm{A}_{\text {control }}\right) \times 100$.

Measurement of melanin content. The release of extracellular melanin was measured as previously described (40), with a slight modification. The B16F10 melanoma cells were seeded overnight in 6 -well plates $\left(1 \times 10^{5}\right.$ cells/well). $\alpha$-MSH $(1 \mu \mathrm{M})$ was then added or BIO for $30 \mathrm{~min}$ prior to the addition of $\alpha$-MSH. The cells were treated with increasing concentra- 


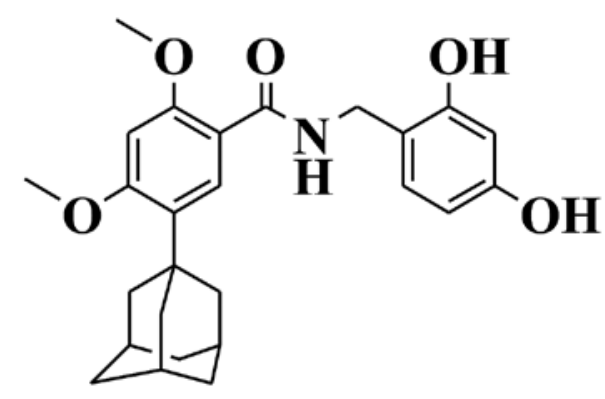

Figure 1. Structure of AP736.

tions of the compound in phenol red-free DMEM for 3 days. Subsequently, $200 \mathrm{ml}$ of the medium were then added to 96-well plates, and the optical density of each culture well was measured at $405 \mathrm{~nm}$ using a spectrophotometer. The data were normalized to the protein content of the cell lysates. The cell lysates were subsequently processed for determination of the protein concentration using a BCA Protein Assay kit (Pierce Biotechnology, Rockford, IL, USA).

Cell-free enzymatic assay for tyrosinase activity. Cell-free enzymatic assay for tyrosinase activity was carried out as previously described (41). Tyrosinase activity was assayed as a function of DOPA oxidase activity. A total of $70 \mathrm{ml}$ of $0.1 \mathrm{M}$ phosphate buffer ( $\mathrm{pH}$ 6.8) containing AP736 and kojic acid in $0.1 \mathrm{M}$ phosphate buffer were mixed with $20 \mathrm{ml}$ of $10 \mu \mathrm{g} / \mathrm{ml}$ mushroom tyrosinase in each well of a 96-well plate, and then $10 \mathrm{ml}$ of $10 \mathrm{mM}$ L-DOPA was added. The absorbance values at $475 \mathrm{~nm}$ were measured every $10 \mathrm{~min}$ for at least $1 \mathrm{~h}$ using a spectrophotometer at an incubation temperature of $37^{\circ} \mathrm{C}$. The quantity of dopachrome formed in the reaction mixture was determined against a blank (solution without enzyme) at $475 \mathrm{~nm}$ in the spectrophotometer. The percentage of tyrosinase activity was calculated as follows: tyrosinase activity $(\%)=[(A-B) /$ $(C-D) \times 100]$, where $A$ is the absorbance of the reaction mixture containing the test sample and mushroom tyrosinase, $B$ is the absorbance of the blank sample containing the test sample but no mushroom tyrosinase, $C$ is the absorbance of the reaction mixture without the test sample and with mushroom tyrosinase, and $D$ is the absorbance of the well lacking both the test sample and mushroom tyrosinase (L-DOPA alone).

Assay of cellular tyrosinase activity. The assay for cellular tyrosinase activity was carried out as previously described (41). Tyrosinase activity was estimated by measuring the rate of L-DOPA oxidation. The B16F10 melanoma cells were incubated at a density of $1 \times 10^{5}$ cells in 6-well plates and treated as indicated for 3 days in DMEM. The cells were then washed in ice-cold PBS and lysed in $100 \mathrm{ml}$ of phosphate buffer $(0.1 \mathrm{M}), \mathrm{pH}$ 6.8 , containing $1 \%(\mathrm{w} / \mathrm{v})$ Triton X-100. The cellular extract was clarified by centrifugation at $15,000 \mathrm{rpm}$ for $20 \mathrm{~min}$. The tyrosinase substrate, L-DOPA $(2 \mathrm{mg} / \mathrm{ml})$, was prepared in the same lysis buffer. Each extract $(200 \mathrm{ml})$ was then placed in a 96-well plate, and the enzymatic assay was initiated by the addition of $2 \mathrm{ml}$ of L-DOPA solution at $37^{\circ} \mathrm{C}$. The control wells contained $200 \mathrm{ml}$ of the lysis buffer. The absorbance at $405 \mathrm{~nm}$ was read every $10 \mathrm{~min}$, for at least $1 \mathrm{~h}$ at $37^{\circ} \mathrm{C}$, using a spectrophotometer.
Tyrosinase activity was calculated using the following formula: tyrosinase activity $(\%)=\mathrm{OD}_{475}$ of sample/OD 475 of control x100.

Western blot analysis. The cells were lysed in cell lysis buffer [62.5 mM Tris-HCl, pH 6.8, 2\% sodium dodecyl sulfate (SDS), $5 \% \beta$-mercaptoethanol, $2 \mathrm{mM}$ phenylmethylsulfonyl fluoride, protease inhibitors (Complete ${ }^{\mathrm{TM}}$; Roche, Mannheim, Germany), $1 \mathrm{mMNa}_{3} \mathrm{VO}_{4}, 50 \mathrm{mM} \mathrm{NaF}$ and $10 \mathrm{mM}$ EDTA]. A $20 \mu \mathrm{g}$ sample of protein per lane was separated by SDS-polyacrylamide gel electrophoresis and blotted onto polyvinylidene fluoride membranes (Millipore, Billerica, MA, USA) which were then saturated with $5 \%$ powdered milk in Tris-buffered saline containing 0.5\% Tween-20 (TBST; Sigma-Aldrich Co.). The blots were then incubated with the appropriate primary antibodies at a dilution of 1:1,000 or 1:2,000, and further incubated with horseradish peroxidase-conjugated secondary antibody. Bound antibodies were detected using enhanced chemiluminescence (Amersham Pharmacia, Piscataway, UK). Images of the blotted membranes were captured using an LAS-1000 lumino-image analyzer (Fujifilm, Tokyo, Japan). Protein levels were compared to those of the appropriate loading control, such as actin or non-phosphorylated protein.

Immunocytochemistry/immunofluorescence (ICC/IF) assay. The B16F10 melanoma cells $\left(3 \times 10^{4}\right)$ were seeded onto glass coverslips that were pre-coated with poly-L-lysine $(0.01$; Sigma-Aldrich Co.). Following incubation for 24 h, ICC/IF was performed. The slides were fixed with $4 \%$ paraformaldehyde for $10 \mathrm{~min}$ at room temperature. After washing with PBS, the cells were permeabilized with $0.01 \%$ Triton X-100 in PBS or TBST for $10 \mathrm{~min}$ at room temperature and then blocked with $2 \%$ bovine serum albumin in PBS for $60 \mathrm{~min}$ at room temperature. The slides were incubated overnight with tyrosinase antibodies at $4^{\circ} \mathrm{C}$. After washing, the slides were incubated with fluorescein isothiocyanate (FITC)-conjugated secondary antibody (Santa Cruz Biotechnology, Inc.), mounted using fluorescent mounting medium with 4',6-diamidino-2-phenylindole (DAPI; Golden Bridge International, Inc., Bothell, WA, USA). Cell morphology was observed under a DP70 fluorescence microscope with DP Controller software (Olympus Optical Co., Ltd., Tokyo, Japan).

Statistical analysis. Statistical analyses were performed using SPSS for Windows, version 18.0 (SPSS Inc., Chicago, IL, USA). The results are expressed as the means \pm standard deviation. Data were analyzed by one-way ANOVA, followed by Duncan's test for multiple comparison. A two-tailed P-value $<0.05$ was considered to indicate a statistically significant difference.

\section{Results}

Effects of AP736 on B16F10 melanoma cell viability. In order to determine whether AP736 inhibits melanogenesis, the B16F10 melanoma cells were treated with the extract prior to $\alpha$-MSH stimulation. However, we first examined the cytotoxicity of AP736 on B16F10 melanoma cells by CCK-8 assay. The B16F10 melanoma cells were treated with AP736 at concentrations of 0.1-10 $\mu \mathrm{M}$ for $24 \mathrm{~h}$. As shown in Fig. 2, AP736 was not cytotoxic at concentrations of 0.1 to $3 \mu \mathrm{M}$. Accordingly, we used 0.1-3 $\mu \mathrm{M}$ AP736 in the subsequent experiments. 


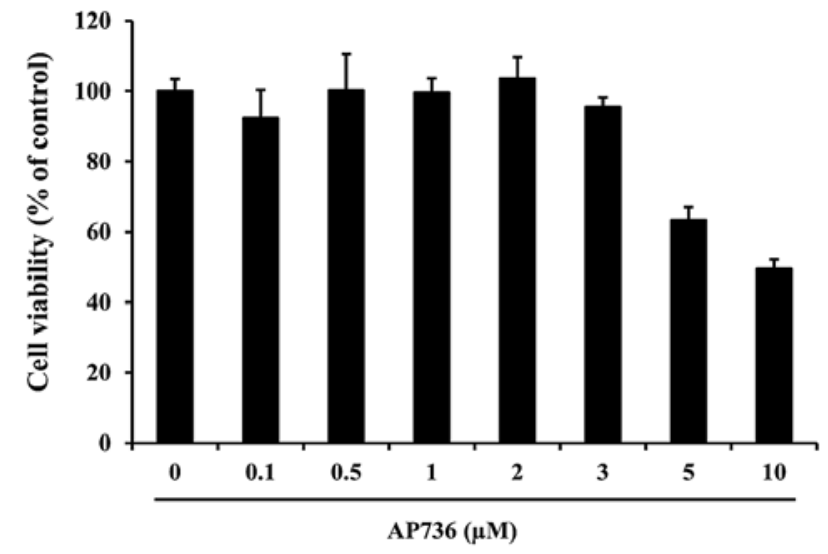

Figure 2. Effects of AP736 on B16F10 melanoma cell viability. Cells were serum-starved for $24 \mathrm{~h}$ and then treated with AP736 at concentrations of $0.1-10 \mu \mathrm{M}$ for $24 \mathrm{~h}$ in serum-free medium. Cell viability was determined by Cell Counting Kit- 8 assays. Each determination was made in triplicate, and the data shown are the means \pm SD.

Effects of AP736 on melanogenesis in B16F10 melanoma cells. The effects of AP736 on the melanogenesis of B16F10 melanoma cells were examined. To determine whether AP736 inhibits $\alpha$-MSH-induced melanin synthesis in B16F10 melanoma cells, we measured $\alpha$-MSH-induced melanin production in B16F10 melanoma cells after 3 days of treatment with AP736 at 1-3 $\mu \mathrm{M}$. As shown in Fig. 3A, the addition of $\alpha-\mathrm{MSH}$ increased the amount of melanin in the medium; however, treatment with AP736 reduced the release of melanin in a dosedependent manner. PTU, a well-known tyrosinase inhibitor, was used as a positive control, as previously described (42).

Melanogenesis is known to be controlled through an enzymatic cascade that is regulated by tyrosinase (43). Thus, to investigate the mechanisms of depigmentation by AP736, we measured tyrosinase activity in both cell-based and cellfree assay systems. As shown in Fig. 3B, the $\alpha-\mathrm{MSH}$-induced tyrosinase activity was inhibited in a dose-dependent manner by AP736 $(1-3 \mu \mathrm{M})$. We also found that treatment with $3 \mu \mathrm{M}$ AP736 reduced tyrosinase activity. Specifically, compared with the untreated cells, treatment with AP736 at a concentration of $3 \mu \mathrm{M}$ resulted in an approximately $33 \%$ inhibition of intracellular tyrosinase in the B16F10 melanoma cells. A number of skin-whitening compounds directly inhibit tyrosinase (44). Thus, to examine the direct effects of AP736 on tyrosinase, we measured the tyrosinase activity of mushroom tyrosinase in a cell-free system, as described in the Materials and methods. AP736 exerted little inhibitory effect on tyrosinase activity; however, treatment with $100 \mu \mathrm{M}$ kojic acid (a direct inhibitor of tyrosinase) exerted a strong inhibitory effect (Fig. 3C). These results indicated that the inhibitory effect of AP736 on melanogenesis was not due to the direct inhibition of tyrosinase.

Effects of AP736 on pathways of melanogenesis in B16F10 melanoma cells. In order to determine whether the inhibitory
$\mathbf{A}$

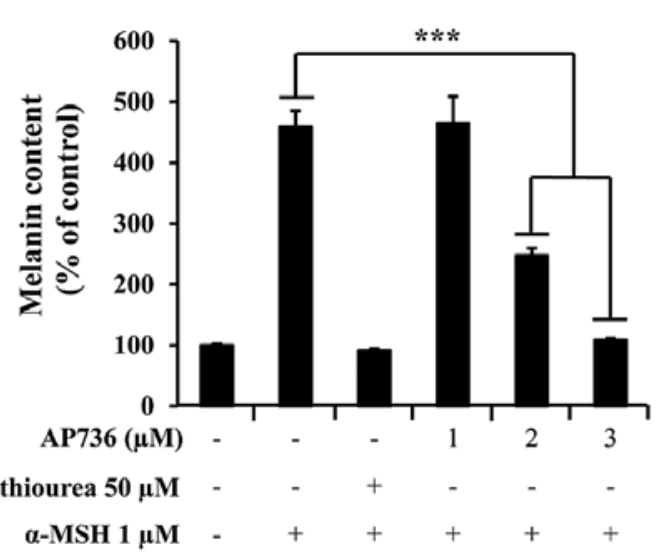

B

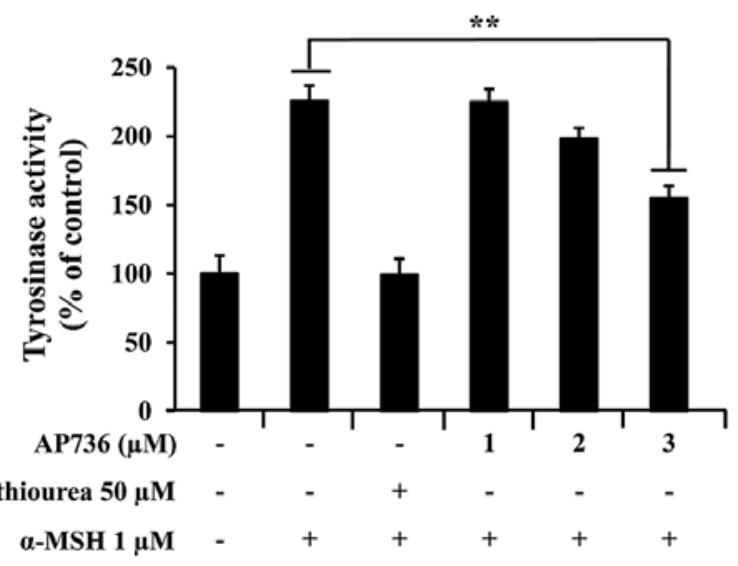

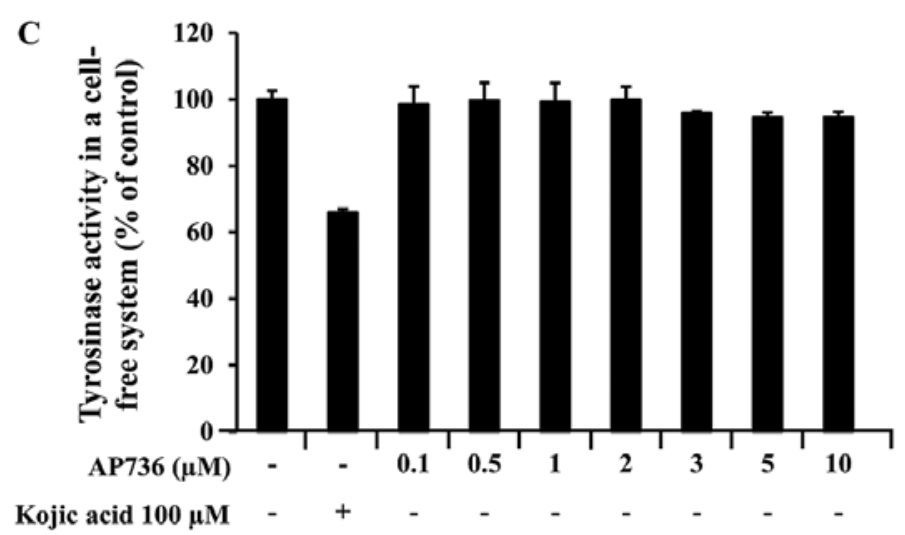

Figure 3. Effects of AP736 on melanogenesis in B16F10 melanoma cells. Cells were co-cultured with $\alpha$-melanocyte-stimulating hormone ( $\alpha$-MSH; $1 \mu$ M), AP736 (0.1-10 $\mu \mathrm{M})$, and phenylthiourea (PTU; $50 \mu \mathrm{M})$ for 3 days. (A) Melanin content, (B) tyrosinase activity, and (C) tyrosinase activity in a cell-free system were measured as described in the Materials and methods. The results shown are the averages of triplicate experiments $\pm \mathrm{SD}$. ${ }^{* *} \mathrm{P}<0.01,{ }^{* * *} \mathrm{P}<0.005$ versus $\alpha$-MSH-treated controls (A and B). 
A

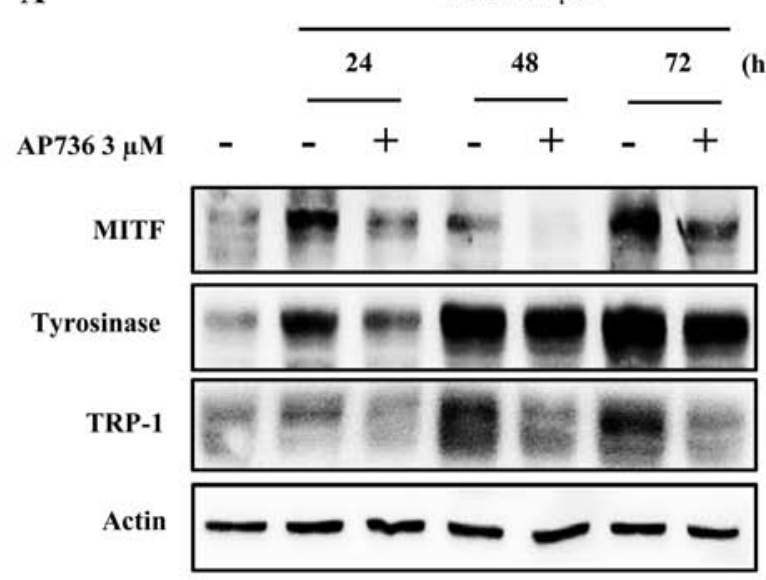

B

(h)

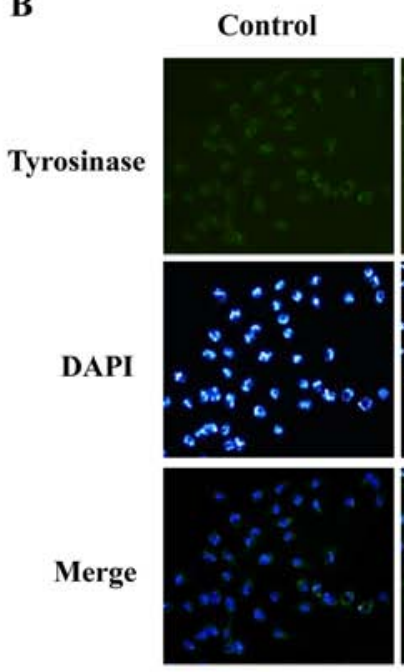

$\alpha$-MSH $1 \mu \mathrm{M}$
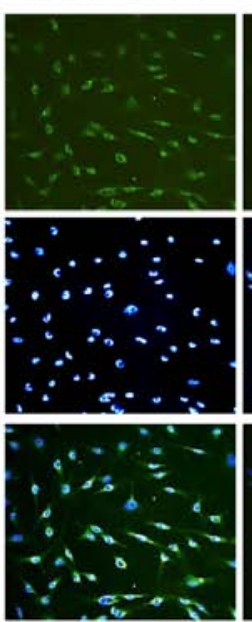

$\alpha$-MSH $1 \mu$ M

$+\mathrm{AP736} 3 \mu \mathrm{M}$

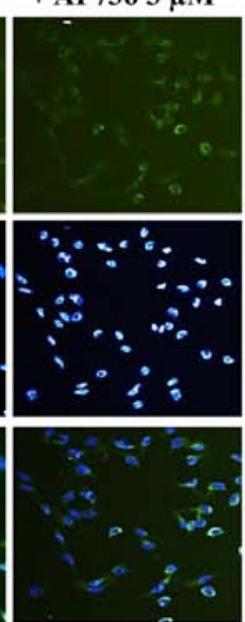

$\times 200$

Figure 4. Effects of AP736 on the protein expression of microphthalmia-associated transcription factor (MITF) and tyrosinase. (A) B16F10 melanoma cells were treated with $\alpha$-melanocyte stimulating hormone $(\alpha-\mathrm{MSH} ; 1 \mu \mathrm{M})$ and AP736 $(3 \mu \mathrm{M})$ for 24-72 h. Whole cell lysates were then subjected to western blot analysis using antibodies against MITF, tyrosinase, and tyrosinase-related protein-1 (TRP-1). Equal protein loadings were confirmed using anti-actin antibody. (B) The expression of tyrosinase was confirmed by immunocytochemistry/immunofluorescence (ICC/IF) staining using specific anti-tyrosinase antibodies (green). Corresponding 4',6-diamidino-2-phenylidole (DAPI) nuclear staining (blue) and the merged images are shown. Fluorescence was detected under a fluorescence microscope. The specimens were photographed using DP Controller software (x200 magnification). The results shown are the averages of triplicate experiments \pm SD.

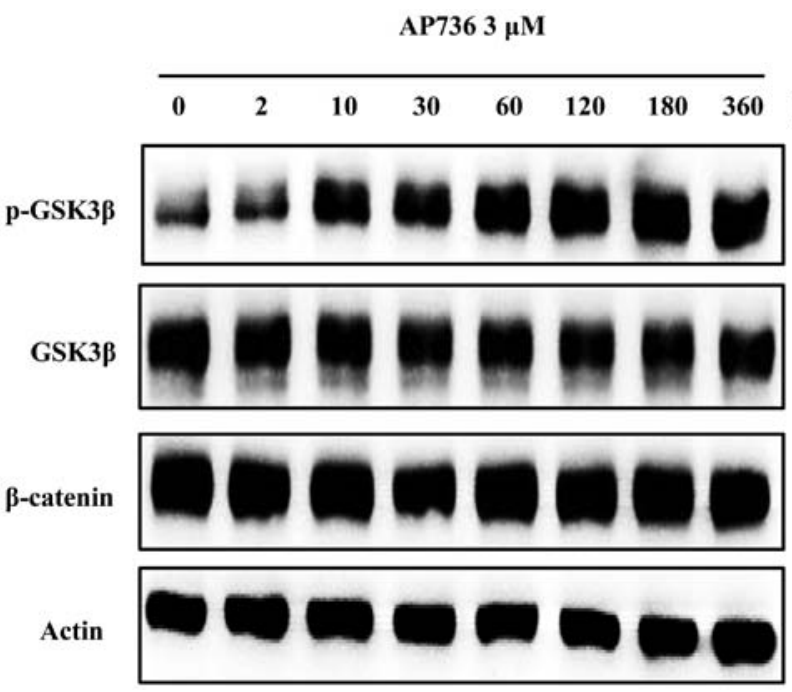

Figure 5. Effects of AP736 on the signal transduction pathways in B16F10 melanoma cells. After $24 \mathrm{~h}$ of serum starvation, B16F10 melanoma cells were treated with $3 \mu \mathrm{M}$ AP736 for the indicated time periods of time. Whole cell lysates were then subjected to western blot analysis using antibodies against phospho-specific glycogen synthase kinase $3 \beta$ (GSK3 $\beta$ ), total GSK3 $\beta$, and $\beta$-catenin. Equal protein loadings were confirmed using GSK3 $\beta$ or actin antibody. The results shown are the averages of triplicate experiments.

activity of AP736 is related to pathways of melanogenesis involving the expression of tyrosinase, TRP-1 and MITF, the B16F10 mouse melanoma cells were treated with AP736 prior to stimulation with $\alpha-\mathrm{MSH}$. The resulting cell lysates were subjected to SDS-PAGE and western blot analysis. As shown in Fig. 4, the MITF levels were markedly decreased following treatment with AP736 for 24-72 h, and the tyrosinase and TRP-1 levels also decreased in a time-dependent manner. These results suggest that AP736 decreases melanin synthesis through the downregulation of MITF and tyrosinase.
Furthermore, the effects of AP736 on tyrosinase expression in the cells was confirmed by ICC/IF assay (Fig. 4B). The results revealed that the level of tyrosinase in the cells was reduced following treatment with AP736 for $72 \mathrm{~h}$ in the presence of $\alpha$-MSH.

Effects of AP736 on signal transduction pathways in B16F10 melanoma cells. To elucidate the mechanisms underlying the hypopigmentary effects of AP736, changes in melanogenesisrelated signals induced by AP736 were examined by western blot analysis in a time-course experiment. AP736 has been reported to show anti-melanogenic activity in melanocytes in vitro and in artificial skin equivalents through the inhibition of key melanogenic enzymes and suppression of the cAMPPKA-CREB signaling pathway (45). Thus, we investigated whether AP736 induces the phosphorylation of GSK3 $\beta$ and the degradation of $\beta$-catenin. We confirmed that GSK3 $\beta$ phosphorylation was clearly induced by treatment with $3 \mu \mathrm{M}$ AP736; however, the $\beta$-catenin levels were not altered (Fig. 5).

Effects of AP736 on GSK3 $\beta$ phosphorylation and melanogenesis. The activation of GSK3 $\beta$ has been reported to inhibit tyrosinase expression (46), which subsequently decreases cellular melanin synthesis. Therefore, experiments were carried out to determine whether the AP736-induced phosphorylation of the GSK $3 \beta$ signaling pathway plays a role in melanin synthesis in B16F10 melanoma cells treated with AP736 for $6 \mathrm{~h}$ in the presence or absence of BIO, a specific GSK3 $\beta$ phosphorylation inhibitor. As shown in Fig. 6A, the cellular melanin content of the cells co-treated with $\alpha-\mathrm{MSH}$ and BIO was higher than that in the cells treated with $\alpha-\mathrm{MSH}$ alone. In addition, this synergistic effect of $\alpha-\mathrm{MSH}$ and $\mathrm{BIO}$ on the cellular melanin content was offset by AP736 treatment. We then examined whether BIO inhibits GSK3 $\beta$ phosphorylation in B16F10 melanoma cells and found that BIO does, in fact, inhibit the phosphorylation of 
A
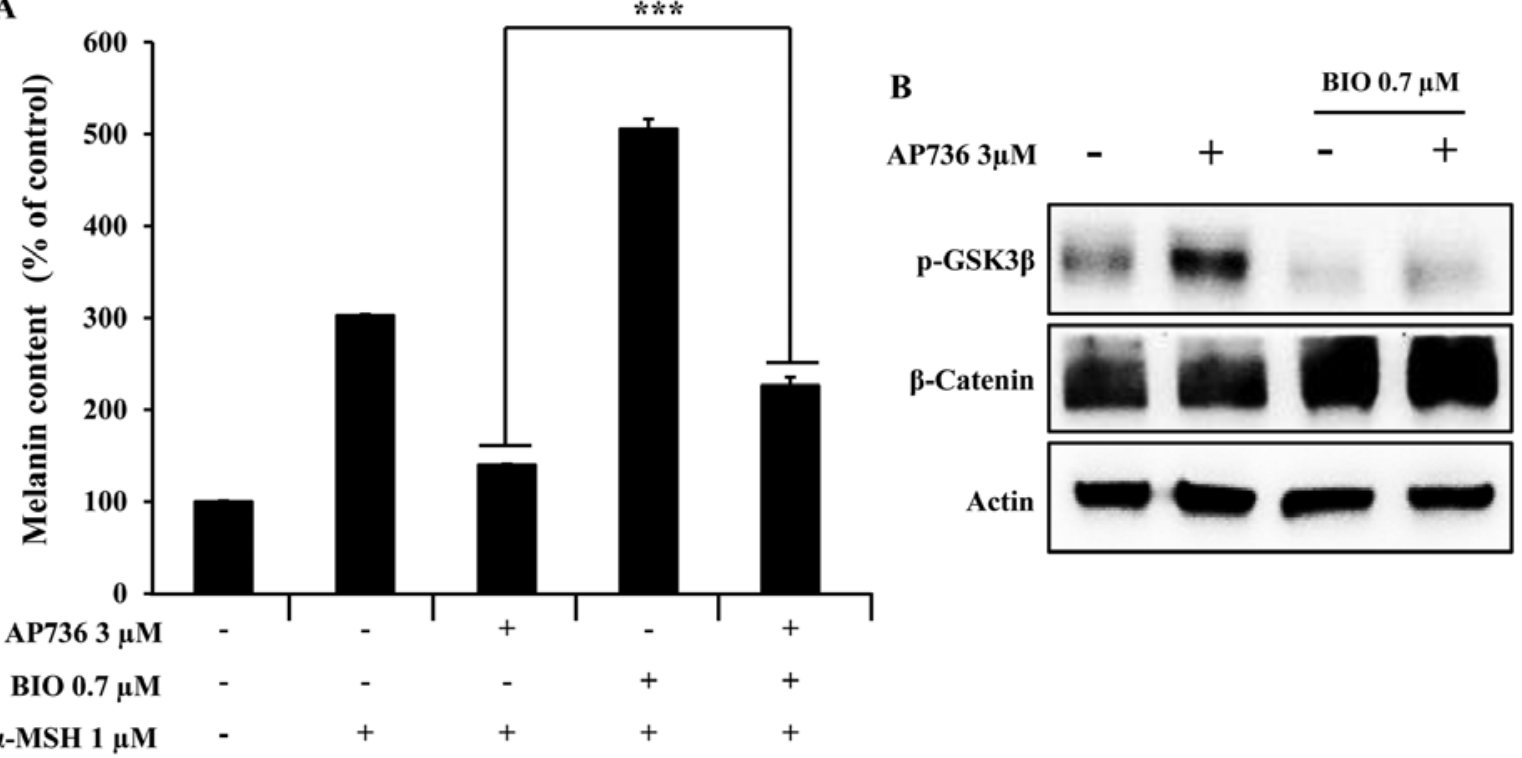

Figure 6. Effects of AP736 on glycogen synthase kinase $3 \beta$ (GSK3 $\beta$ ) phosphorylation and melanogenesis. (A) B16F10 melanoma cells were treated with AP736 $(3 \mu \mathrm{M})$ in the presence or absence of (2'Z,3'E)-6-bromoindirubin-3'-oxime (BIO; $0.7 \mu \mathrm{M})$ after adding $\alpha$-melanocyte stimulating hormone $(\alpha-\mathrm{MSH}$; $1 \mu \mathrm{M})$ for 3 days. The melanin content was measured. Each determination was made in triplicate. The data shown represent the means $\pm \mathrm{SD}$. ${ }^{* * *} \mathrm{P}<0.005$ compared with the AP736-treated group. (B) Cells were cultured with AP736 $(3 \mu \mathrm{M})$ for $6 \mathrm{~h}$ in the presence or absence of BIO $(0.7 \mu \mathrm{M})$. Whole cell lysates were then subjected to western blot analysis with antibodies against phospho-specific glycogen synthase kinase $3 \beta$ (GSK3 $\beta$ ) or $\beta$-catenin. Equal protein loading was confirmed using actin antibody. The results shown are the averages of triplicate experiments.

GSK3 $\beta$ in the AP736-treated B16F10 melanoma cells (Fig. 6B). These results clearly indicate that GSK3 $\beta$ phosphorylation is involved in the inhibition of melanogenesis by AP736.

\section{Discussion}

The majority of depigmenting compounds act specifically to reduce the function of tyrosinase through several mechanisms which include interference with its transcription and/ or glycosylation, enzyme inhibition, reduction of by-products, and post-transcriptional control. Some compounds inhibit melanosome transfer from melanocytes to keratinocytes and accelerate skin turnover $(47,48)$. The exploration of compounds that act on the inhibition of melanin synthesis would be helpful in understanding and studying the precise role of the related signal transduction pathways and their function in melanogenesis. Thus, in this study, the effects of AP736 on melanin synthesis and related signaling pathways were investigated using B16F10 melanoma cells.

This study demonstrates that AP736 is a skin-whitening compound that acts via the downregulation of tyrosinase, TRP-1 and MITF expression. The inhibitory effects of AP736 were dose-dependent and did not incur significant cytotoxicity (Fig. 2). The AP736-induced decrease in melanin production was also accompanied by a corresponding decrease in tyrosinase activity, suggesting a possible mechanism of AP736 action (Fig. 3). Tyrosinase has been demonstrated to catalyze the rate-limiting step of melanin biosynthesis, and it is the primary target of PTU, which is an agent with efficient depigmenting effects currently used for cosmetic and medical purposes (49). AP736 markedly inhibited intracellular tyrosinase activity in the $\alpha$-MSH-stimulated B16F10 melanoma cells, as demonstrated by cellular tyrosinase (Fig. 3B). However, as shown in Fig. 3C, AP736 did not directly inhibit tyrosinase activity, indicating the involvement of different mechanisms. These results suggest that the decrease in pigmentation induced by AP736 may be attributed to its effect on the signaling pathways regulating tyrosinase.

For a better understanding of the depigmenting effect of AP736 and the way in which tyrosinase synthesis is targeted, western blot analysis was carried out. Our data confirmed that the MITF, tyrosinase and TRP-1 protein levels were decreased by AP736 in a time-dependent manner (Fig. 4A). In addition, the AP736-induced hypopigmentation correlated with reduced tyrosinase activity (Fig. 3A and B), which could be responsible for the hypopigmentation of AP736-treated cells. Furthermore, the effect of AP736 on tyrosinase expression in B16F10 melanoma cells was confirmed by ICC/IF (Fig. 4B). The results revealed that the tyrosinase level in B16F10 melanoma cells was reduced by treatment with AP736 for $72 \mathrm{~h}$ in the presence of $\alpha$-MSH. To elucidate the mechanisms underlying the hypopigmentary effects of AP736, changes in melanogenesis-related signals induced by AP736 were examined by western blot analyiss in a time-course experiment (Fig. 5).

MITF expression is also induced by GSK $3 \beta$ inactivation (phosphorylation) and subsequent $\beta$-catenin accumulation $(50,51)$. By contrast, it has been reported that activated (dephosphorylated) GSK3 $\beta$ phosphorylates MITF at Ser298 in melanoma cells and melanocytes. Furthermore, the phosphorylation of MITF at Ser298 significantly increases its ability to bind to the tyrosinase promoter DNA element, resulting in increased melanin synthesis $(23,25,52)$. Thus, in this study, we investigated the possible involvement of GSK3 $\beta$ in tyrosinase expression. In the GSK3 $\beta$-dependent pathway, GSK $3 \beta$, which forms a destruction complex with adenomatous polyposis coli and axin, phosphorylates the $\mathrm{N}$-terminal Ser/Thr 
residues of $\beta$-catenin (53), resulting in its degradation through a ubiquitin-dependent mechanism (54). The N-terminal Ser/Thr residues of $\beta$-catenin are also phosphorylated by protein kinase $\mathrm{C}(\mathrm{PKC}) \alpha$, leading to ubiquitin-dependent $\beta$-catenin degradation (55). In the Siah-dependent pathway, Siah-1 interacts with the carboxyl terminus of adenomatous polyposis coli, which recruits the ubiquitination complex and promotes the degradation of $\beta$-catenin (56). In this study, we found that treatment with a specific GSK3 $\beta$ pathway inhibitor, BIO, reversed the AP736-induced hypopigmentation (Fig. 6). The results of our study also demonstrated that AP736 induced GSK3 $\beta$ phosphorylation and reduced the MITF protein level. To the best of our knowledge, this is the first study to demonstrate the induction of GSK $3 \beta$ phosphorylation by AP736. To investigate the association between GSK3 $\beta$ phosphorylation and MITF downregulation, we treated the cells with BIO prior to treatment with AP736, re-examined the p-GSK3 $\beta$ level, and found that GSK $3 \beta$ inactivation suppressed melanogenesis in B16F10 melanoma cells.

In conclusion, in this study, we demonstrated that treatment with AP736 led to GSK3 $\beta$ phosphorylation, which may have reduced the binding affinity of MITF and subsequently decreased the tyrosinase level. Our data suggest that AP736 may prove to be useful as a novel skin-whitening compound by decreasing the level of tyrosinase.

\section{References}

1. Eves PC, MacNeil S and Haycock JW: alpha-Melanocyte stimulating hormone, inflammation and human melanoma. Peptides 27 444-452, 2006.

2. Yokota T, Nishio H, Kubota Y and Mizoguchi M: The inhibitory effect of glabridin from licorice extracts on melanogenesis and inflammation. Pigment Cell Res 11: 355-361, 1998.

3. Eller MS, Ostrom K and Gilchrest BA: DNA damage enhances melanogenesis. Proc Natl Acad Sci USA 93: 1087-1092, 1996.

4. Wong G and Pawelek J: Melanocyte-stimulating hormone promotes activation of pre-existing tyrosinase molecules in Cloudman S91 melanoma cells. Nature 255: 644-646, 1975.

5. Halaban R, Pomerantz SH, Marshall S and Lerner AB Tyrosinase activity and abundance in Cloudman melanoma cells. Arch Biochem Biophys 230: 383-387, 1984.

6. Hunt G, Todd C, Cresswell JE and Thody AJ: Alpha-melanocyte stimulating hormone and its analogue Nle4DPhe7 alpha-MSH affect morphology, tyrosinase activity and melanogenesis in cultured human melanocytes. J Cell Sci 107: 205-211, 1994.

7. Kanwar AJ, Dhar S and Kaur S: Treatment of melasma with potent topical corticosteroids. Dermatology 188: 170, 1994.

8. Körner A and Pawelek J: Mammalian tyrosinase catalyzes three reactions in the biosynthesis of melanin. Science 217: 1163-1165, 1982.

9. Boissy RE: Melanosome transfer to and translocation in the keratinocyte. Exp Dermatol 12 (Suppl 2): S5-S12, 2003.

10. Buscà R, Bertolotto $\mathrm{C}$, Ortonne JP and Ballotti R: Inhibition of the phosphatidylinositol 3-kinase/p70(S6)-kinase pathway induces B16 melanoma cell differentiation. J Biol Chem 271: 31824-31830, 1996.

11. Costin GE and Hearing VJ: Human skin pigmentation: melanocytes modulate skin color in response to stress. FASEB J 21: 976-994, 2007.

12. Hearing VJ and Tsukamoto K: Enzymatic control of pigmentation in mammals. FASEB J 5: 2902-2909, 1991.

13. Jung E, Lee J, Huh S, Lee J, Kim YS, Kim G and Park D: Phloridzin-induced melanogenesis is mediated by the cAMP signaling pathway. Food Chem Toxicol 47: 2436-2440, 2009.

14. Yasumoto K, Yokoyama K, Takahashi K, Tomita Y and Shibahara S: Functional analysis of microphthalmia-associated transcription factor in pigment cell-specific transcription of the human tyrosinase family genes. J Biol Chem 272: 503-509, 1997.
15. Steingrímsson E, Moore KJ, Lamoreux ML, Ferré-D'Amaré AR, Burley SK, Zimring DC, Skow LC, Hodgkinson CA, Arnheiter H, Copeland NG, et al: Molecular basis of mouse microphthalmia (mi) mutations helps explain their developmental and phenotypic consequences. Nat Genet 8: 256-263, 1994.

16. Tachibana M: MITF: A stream flowing for pigment cells. Pigment Cell Res 13: 230-240, 2000.

17. Vakhedi AS: Biological sutures in ophthalmological microsurgery. Vestn Oftalmol 5: 27-31, 1976 (In Russian).

18. Jiménez-Cervantes C, Martínez-Esparza M, Pérez C, Daum N, Solano F and García-Borrón JC: Inhibition of melanogenesis in response to oxidative stress: transient downregulation of melanocyte differentiation markers and possible involvement of microphthalmia transcription factor. J Cell Sci 114: 2335-2344, 2001.

19. Corre S, Primot A, Sviderskaya E, Bennett DC, Vaulont S, Goding CR and Galibert MD: UV-induced expression of key component of the tanning process, the POMC and MC1R genes, is dependent on the p-38-activated upstream stimulating factor-1 (USF-1). J Biol Chem 279: 51226-51233, 2004.

20. Wu M, Hemesath TJ, Takemoto CM, Horstmann MA, Wells AG, Price ER, Fisher DZ and Fisher DE: c-Kit triggers dual phosphorylations, which couple activation and degradation of the essential melanocyte factor Mi. Genes Dev 14: 301-312, 2000.

21. Xu W, Gong L, Haddad MM, Bischof O, Campisi J, Yeh ET and Medrano EE: Regulation of microphthalmia-associated transcription factor MITF protein levels by association with the ubiquitin-conjugating enzyme hUBC9. Exp Cell Res 255: $135-143,2000$.

22. Kim DS, Hwang ES, Lee JE, Kim SY, Kwon SB and Park KC: Sphingosine-1-phosphate decreases melanin synthesis via sustained ERK activation and subsequent MITF degradation. J Cell Sci 116: 1699-1706, 2003.

23. Larue L and Delmas V: The WNT/Beta-catenin pathway in melanoma. Front Biosci 11: 733-742, 2006.

24. Wu J, Saint-Jeannet JP and Klein PS: Wnt-frizzled signaling in neural crest formation. Trends Neurosci 26: 40-45, 2003.

25. Bellei B, Flori E, Izzo E, Maresca V and Picardo M: GSK3beta inhibition promotes melanogenesis in mouse B16 melanoma cells and normal human melanocytes. Cell Signal 20: 1750-1761, 2008.

26. Giles RH, van Es JH and Clevers H: Caught up in a Wnt storm: Wnt signaling in cancer. Biochim Biophys Acta 1653: 1-24, 2003.

27. Korinek V, Barker N, Morin PJ, van Wichen D, de Weger R, Kinzler KW, Vogelstein B and Clevers H: Constitutive transcriptional activation by a beta-catenin-Tcf complex in APC-/- colon carcinoma. Science 275: 1784-1787, 1997.

28. Morin PJ, Sparks AB, Korinek V, Barker N, Clevers H, Vogelstein B and Kinzler KW: Activation of beta-catenin-Tcf signaling in colon cancer by mutations in beta-catenin or APC. Science 275: 1787-1790, 1997.

29. Wodarz A and Nusse R: Mechanisms of Wnt signaling in development. Annu Rev Cell Dev Biol 14: 59-88, 1998.

30. Polakis P: Wnt signaling and cancer. Genes Dev 14: 1837-1851, 2000.

31. Liu C, Li Y, Semenov M, Han C, Baeg GH, Tan Y, Zhang Z, Lin X and He X: Control of beta-catenin phosphorylation/degradation by a dual-kinase mechanism. Cell 108: 837-847, 2002.

32. Amit S, Hatzubai A, Birman Y, Andersen JS, Ben-Shushan E, Mann M, Ben-Neriah Y and Alkalay I: Axin-mediated CKI phosphorylation of beta-catenin at Ser 45: a molecular switch for the Wnt pathway. Genes Dev 16: 1066-1076, 2002.

33. Latres E, Chiaur DS and Pagano M: The human F box protein beta-Trcp associates with the Cul1/Skp1 complex and regulates the stability of beta-catenin. Oncogene 18: 849-854, 1999.

34. Lee E, Salic A, Krüger R, Heinrich R and Kirschner MW: The roles of APC and Axin derived from experimental and theoretical analysis of the Wnt pathway. PLoS Biol 1: E10, 2003.

35. Takeda K, Yasumoto K, Takada R, Takada S, Watanabe K, Udono T, Saito H, Takahashi K and Shibahara S: Induction of melanocyte-specific microphthalmia-associated transcription factor by Wnt-3a. J Biol Chem 275: 14013-14016, 2000.

36. Schepsky A, Bruser K, Gunnarsson GJ, Goodall J, Hallsson JH, Goding CR, Steingrimsson E and Hecht A: The microphthalmiaassociated transcription factor Mitf interacts with beta-catenin to determine target gene expression. Mol Cell Biol 26: 8914-8927, 2006.

37. Parvez S, Kang M, Chung HS, Cho C, Hong MC, Shin MK and Bae H: Survey and mechanism of skin depigmenting and lightening agents. Phytother Res 20: 921-934, 2006. 
38. Shimizu K, Yasutake S and Kondo R: A new stilbene with tyrosinase inhibitory activity from Chlorophora excelsa. Chem Pharm Bull (Tokyo) 51: 318-319, 2003.

39. Park SH, Kim DS, Kim WG, Ryoo IJ, Lee DH, Huh CH, Youn SW Yoo ID and Park KC: Terrein: A new melanogenesis inhibitor and its mechanism. Cell Mol Life Sci 61: 2878-2885, 2004.

40. Kim DS, Jeong YM, Park IK, Hahn HG, Lee HK, Kwon SB, Jeong JH, Yang SJ, Sohn UD and Park KC: A new 2-imino1,3-thiazoline derivative, KHG22394, inhibits melanin synthesis in mouse B16 melanoma cells. Biol Pharm Bull 30: 180-183, 2007.

41. Lee do H, Kim DH, Oh IY, Kim SY, Lim YY, Kim HM, Kim YH Choi YM, Kim SE, Kim BJ and Kim MN: Inhibitory effects of Saururi chinensis extracts on melanin biosynthesis in B16F10 melanoma cells. Biol Pharm Bull 36: 772-779, 2013.

42. Poma A, Bianchini S and Miranda M: Inhibition of L-tyrosine-induced micronuclei production by phenylthiourea in human melanoma cells. Mutat Res 446: 143-148, 1999.

43. Casanola-Martin GM, Le-Thi-Thu H, Marrero-Ponce Y Castillo-Garit JA, Torrens F, Rescigno A, Abad C and Khan MT: Tyrosinase enzyme: 1 . An overview on a pharmacological target. Curr Top Med Chem 14: 1494-1501, 2014.

44. Smit N, Vicanova J and Pavel S: The hunt for natural skin whitening agents. Int J Mol Sci 10: 5326-5349, 2009.

45. Lee CS, Jang WH, Park M, Jung K, Baek HS, Joo YH, Park YH and Lim KM: A novel adamantyl benzylbenzamide derivative, AP736, suppresses melanogenesis through the inhibition of cAMP-PKA-CREB-activated microphthalmia-associated transcription factor and tyrosinase expression. Exp Dermatol 22: 762-764, 2013

46. Lin YS, Chuang MT, Chen CH, Chien MY and Hou WC: Nicotinic acid hydroxamate downregulated the melanin synthesis and tyrosinase activity through activating the MEK/ERK and AKT/GSK3 $\beta$ signaling pathways. J Agric Food Chem 60: 4859-4864, 2012.

47. Gillbro JM and Olsson MJ: The melanogenesis and mechanisms of skin-lightening agents - existing and new approaches. Int J Cosmet Sci 33: 210-221, 2011.
48. Son $\mathrm{KH}$ and Heo MY: The evaluation of depigmenting efficacy in the skin for the development of new whitening agents in Korea. Int J Cosmet Sci 35: 9-18, 2013.

49. Land EJ, Ramsden CA, Riley PA and Stratford MR: Evidence consistent with the requirement of cresolase activity for suicide inactivation of tyrosinase. Tohoku J Exp Med 216: 231-238, 2008.

50. Grabacka M, Placha W, Urbanska K, Laidler P, Płonka PM and Reiss K: PPAR gamma regulates MITF and beta-catenin expression and promotes a differentiated phenotype in mouse melanoma S91. Pigment Cell Melanoma Res 21: 388-396, 2008.

51. Grabacka M, Plonka PM, Urbanska K and Reiss K: Peroxisome proliferator-activated receptor alpha activation decreases metastatic potential of melanoma cells in vitro via down-regulation of Akt. Clin Cancer Res 12: 3028-3036, 2006.

52. Takeda K, Takemoto C, Kobayashi I, Watanabe A, Nobukuni Y, Fisher DE and Tachibana M: Ser298 of MITF, a mutation site in Waardenburg syndrome type 2, is a phosphorylation site with functional significance. Hum Mol Genet 9: 125-132, 2000.

53. Hart MJ, de los Santos R, Albert IN, Rubinfeld B and Polakis P: Downregulation of beta-catenin by human Axin and its association with the APC tumor suppressor, beta-catenin and GSK3 beta. Curr Biol 8: 573-581, 1998.

54. Aberle H, Bauer A, Stappert J, Kispert A and Kemler R: betacatenin is a target for the ubiquitin-proteasome pathway. EMBO J 16: 3797-3804, 1997.

55. Gwak J, Cho M, Gong SJ, Won J, Kim DE, Kim EY, Lee SS, Kim M, Kim TK, Shin JG and Oh S: Protein-kinase-C-mediated beta-catenin phosphorylation negatively regulates the Wnt/betacatenin pathway. J Cell Sci 119: 4702-4709, 2006.

56. Liu J, Stevens J, Rote CA, Yost HJ, Hu Y, Neufeld KL, White RL and Matsunami N: Siah-1 mediates a novel beta-catenin degradation pathway linking p53 to the adenomatous polyposis coli protein. Mol Cell 7: 927-936, 2001. 